\title{
INTEGRASI PENDIDIKAN KARAKTER, REVOLUSI MENTAL DAN NILAI-NILAI BUDAYA BIMA
}

\author{
Edy Suparjan, Nurnaningsih \\ STKIP Taman Siswa Bima \\ Email: tanmaedysu@gmail.com
}

\begin{abstract}
Abstrak:
Pendidikan karakter merupakan orientasi akhir dari penyelenggaran penddikan baik pada jenjang pendidikan formal, non-formal,dan in-formal. Pengembangan pendidikan karakter juga menjadi matarantai yang tidak terpisahkan teramsuk dalam rumusan pengembangan kurijkulum nasional. Disisi lain, pengembangan pendidikan karakter juga merupakan hasil rumusan integrasi dari berbagai aspek kehidupan social masyarakat mulai dari adat-istiadat, pandangan kebudayaan dan proyeksi capaian pendidikan nasional sehingga menjadi satu kesatuan integratif dalam menyelenggaran pendidikan karakter di lingkup satuan pendidikan. Dalam hal inilah, integrasi pendidikan karakter, revolusi mental dan nilai-nilai budaya Bima penting untuk dipahami agara dapat dijadikan acuan penyelenggaraan pendidikan berbasis budaya Bima bagi seluruh stakeholder dilingkup satuan pendidikan di daerah Bima. Dengan demikian, penguatan intergasi pendidikan karakter dan nilai budaya Bima yang selaras dengan capaian pendidikan nasional diharapkan akan berdampak positif terhadap pembentukan karakter, sikap, dan tingkah laku paripurna seorang anak/siswa dilingkup satuan pendidikan dan dilingkup kehidupan sosialnya.
\end{abstract}

Kata Kunci: Integrasi, Pendidikan Karakter, Nila Budaya Bima.

\section{Pendahuluan}

ecara umum terminologi pendidikan adalah usaha memanusiakan manusia dengan kata lain agar menjadi manusia paripurna. Dalam hal ini, sudah selayaknya bahwa pendidikan menjadi tanggungjawab siapapun termasuk pranata keluarga sebagai yang pertama sekali mendidik dan membentuk moral dan karakter peserta didik. Peran orangtua sebagai tokoh teladan sangat berpengaruh bagi pembentukan karakter peserta didik. Agar pendidikan nasional kita seimbang dalam pelaksanaannya, Undang-undang Nomor 02 Tahun 2003 pada pasal 13 ayat 1 menyebutkan bahwa jalur pendidikan terdiri atas pendidikan formal, nonformal dan informal. Ketiga aspek jalur pendidikan tersebut tidak boleh kita abaikan satu sama lain. ${ }^{1}$ Ketiga jalur pendidikan tersebut wajib bersinergi dalam mewujudkan cita-cita pendidikan nasional kita. Ironisnya sekarang ini, pemerintah selalu fokus pada pendidikan formal, bahkan pendidikan informal jalur pendidikan keluarga kurang diperhatikan, inilah yang menjadi problemnya.

${ }^{1}$ Republik Indonesia, "Undang-Undang RI Nomor 20 Tahun 2003 tentang Sistem Pendidikan Nasional” (Cet. V; Jakarta: Sinar Grafika, 2013), 12 
Dalam aspek kognitif pendidikan kita sangat sukses banyak peserta didik Indonesia yang menjadi juara dalam olimpiade skala regional maupun Internasional. Namun ironisnya, dalam aspek perilaku dan karakter generasi kita semakin jauh dari ahlak dan moralitas serta identitas kebangsaan kita mulai hilang seiring dengan perkembangan globalisasi saat ini. Pendidikan karakter hanyalah sebatas konsep, kekerasan demi kekerasan mulai menghantui dunia pendidikan, diberbagai media massa dan online selalu kita baca dan nonton perilaku kekerasan siswa sesama siswa, orangtua siswa dengan guru, siswa dengan guru. Ini berarti pendidikan kita belum maksimal implementasinya dilapangan. Beberapa aturan memang telah dibuat dan sahkan. Namun, implementasinya tingkat bawah tidak tuntas, evaluasi pun jarang dilakukan. Contohnya saja Permendikbud Nomor 23 Tahun 2015 Tentang Penumbuhan Budi Pekerti. Kemudian Instruksi Presiden Nomor 12 Tahun 2016 Tentang Gerakan Nasional Revolusi Mental (GNRM). Kedua aturan tersebut, dalam beberapa hal sudah dilaksanakan, akan tetapi tidak seimbang. Misalnya siswa disekolah rajin sholat, rajin belajar, mengikuti iklim dzikir ketika kembali kerumah atau di masyarakat siswa tersebut tidak membudayakan hal tersebut, orangtua cenderung apatis. Begitupun juga dengan revolusi mental yang dicanangkan oleh Presiden Jokowi dari atas sangatlah bagus, ketika sampai di daerah konsep tersebut belum diterapkan secara maksimal, contohnya di Daerah Bima belum ada sinkronisasi Revolusi Mental dengan program daerah maupun instansi. Selain itu, sekolah belum memiliki upaya maksimal membudayakan gerakan revolusi mental di sekolah sebagai metode pembudayaan kepada peserta didik.

Untuk itu, tulisan ini mencoba menelaah konsep-konsep yang tertuang dalam dokumen peraturan maupun buku-buku referensi serta nilai-nilai budaya yang berlaku dan hidup di masyarakat Bima, dilihat korelasi dan keterkaitannya sehingga digabung menjadi sebuah formulasi baru bagi kemajuan pendidikan nasional kita. Penulis melihat ada keterkaitan yang sangat vital antara pendidikan karakter, revolusi mental dan nilai-nilai budaya Bima. Sehingga sangat penting diuraiakan dalam tulisan ini sebagai upaya membangun konsep baru dalam implementasi pendidikan karakter di sekolah.

\section{Metode Penelitian}

Penelitian ini menggunakan metode deskriptif ${ }^{2}$ dengan pendekatan studi dokumen. Data yang digunakan adalah data sekunder berupa telaah Permendikbud Nomor 23 Tahun 2015, Inpres Nomor 12 Tahun 2016 serta teori-teori dan konsepkonsep yang bersumber dari buku. Penelaahan dokumen dimaksudkan untuk

\footnotetext{
${ }^{2}$ Menurut Whitney dalam Natzir, (2014 : 43) metode deskripstif adalah pencarian fakta dengan interpretasi yang tepat. Penelitian deskriptif mempelajari masalah-masalah dalam masyarakat serta tata cara yang berlaku dalam masyarakat dan situasi-situasi tertentu, termasuk tentang hubungan, kegiatan-kegiatan, sikap-sikap, pandangan-pandangan, serta proses-proses yang sedang berlangsung dan pengaruh-pengaruh dari suatu fenomena.
} 
memverifikasi data misalnya mengenai bentuk ejaan dan judul. Penelitian ini bertujuan mengetahui, menganalisis dan memahami kesamaan atau hubungan pendidikan karakter, revolusi mental dan nilai-nilai budaya Bima serta bagaimana pelaksanaannya di sekolah.

\section{Pembahasan}

\section{Konsep Dasar Pendidikan Karakter}

Karakter adalah sifat, tabeat, perilaku individu yang dibiasakan menjadi pribadi, menjadi ahlak sehingga terbentuk menjadi karakter. Perilaku individu yang menjadi kerpibadian inilah yang dimaksud dengan karakter. Sehingga membedakannnya dengan individu lain. Menurut Lickona, terdapat tiga elemen pembentukan karakter yaitu; pengetahuan moral, perasaan moral dan tindakan moral.

1. Pengetahuan moral; kesadaran moral, mengetahui nilai moral, kemampuan memahami orang lain, kemampuan memahami makna moral.

2. Perasaan moral; dalam diri individu ada kesadaran, memiliki harga diri, empati terhadap orang lain dan selalu mencintai kebaikan.

3. Tindakan moral; kemampuan untuk mentransformasikan keputusan moral dan menjadi tindakan moral. Komitmen melakukan tindakan, komitemen moral menjadikan sebagai kebiasaan hidup. ${ }^{3}$

Menurut Broks dan Gooble dalam Suyanto, juga mengemukakan pendapat yang sama bahwa terdapat tiga pendekatan mengajarkan karakter di sekolah yaitu;

1. Sekolah harus dipandang sebagai suat lingkungan yang diibaratkan seperti pulau dengan bahasa dan budayanya sendiri.

2. Dalam menjalankan kurikulum karakter, maka sebaiknya pengajaran tentang nilai-nilai berhubungan dengan sistem sekolah secara keseluruhan; diajarkan sebagai subyek yang berdiri sendiri. ${ }^{4}$

Selanjutnya dalam jabaran hasil penelitian Joseph Zins sebagaimana dikutip Muschlih Masnur juga menjelaskan beberapa faktor resiko penyebab kegagalan anak di sekolah, bukan bersumber dari kecerdasan otak, namun banyak ditimbulkan akibat rasa percaya diri yang kurang, kemampuan bekerjasama, bergaul, rasa empati dan kegagalan berkomunikasi. ${ }^{5}$ Dengan demikian dalam hemat penulis, bahwa hakikat utama pendidikan karakter sesungguhnya berorinetasi pada pembentukan sikap dan kesadaran tindakan yang mencerminakan kebaikan dalam diri seorang anak terutama dari aspek pengetahuan moral dan etika dalam kehidupan sosialnya.

${ }^{3}$ Thomas Lickona, Education For Character; How Our School Can Teach Respect and Responsibility (New York: Bantam Books, 1991).

${ }^{4}$ Suyanto. Pendidikan Karakter Teori dan Aplikasi (Jakarta : Rineka Cipta, 2010), 65.

${ }^{5}$ Musclih Masnur. Pendidikan Karakter (Jakarta : Bumi Aksara, 2011), 82-83 


\section{Pendidikan Karakter Di Sekolah}

Jika kita mengacu pada Desain Induk Pendidikan Karakter yang dirancang Kementerian Pendidikan Nasional, strategi pokoknya adalah melalui transformasi budaya sekolah (School Culture) dan habituasi melalui kegiatan esktarkurikuler. ${ }^{6}$ Selanjutnya, Pusat Kurikulum Kementerian Pendidikan Nasional, (2011) dalam pengembangan budaya sekolah minimal ada empat hal pokok yang harus dilaksanakan meliputi;

1. Kegiatan rutin;

2. Kegiatan spontan;

3. Keteladanan;

4. Pengondisian. ${ }^{7}$

Jika kita mengacu pada konsep Lickona bahwa pendekatan dan metode dalam pembelajaran yang sangat cocok dengan pendidikan karakter adalah bagaimana seorang guru menggunakan beberapa metode bercerita kisah-kisah, karakter tokoh yang baik, metode bermain peran serta peserta didik diberikan tugas untuk berdebat tentang moral. Dari sebelas point pendidikan karakter yang ditawarkan oleh Lickona selain memberikan definisi tuntas mengenai karakter kepada peserta didik, bagaimana guru selalu proaktif menciptakan suasana yang benar-benar membuat lingkungan berkarakter, tentu hal ini membutuhkan keterlibatan semua pihak yang ada dalam lingkungan sekolah mulai dari kepala sekolah, guru, pegawai, peserta didik, orangtua sampai masyarakat. Jika kesemuanya ini telah dijalankan dengan baik, pihak sekolah tidak boleh melupakan evaluasi tiap semester bila perlu pertriwulan dan sekolah harus membuat raport karakter siswa yang dievaluasi oleh Guru, komite sekolah dan orangtua peserta didik. ${ }^{8}$

Sebagai pelaksana di sekolah Penumbuhan Budi Pekerti atau Pendidikan karakter Kementerian Pendidikan dan Kebudayaan telah mengaturnya dalam Permendikbud Nomor 23 Tahun 2015 Tentang Penumbuhan Budi Pekerti, pada pasal 3 disebutkan bahwa pelaksana PBP antara lain; 1) Siswa /peserta didik, 2) Guru, 3) Tenaga kependidikan, 4) Orangtua/ Wali murid, 5) Komite sekolah dan 6) Alumni. Bahkan Menarik apa yang disampaikan oleh Najela Shihab dalam Webinar yang dilaksanakan oleh Kementerian Pendidikan Kebudayaan pada tanggal 23 Juni 2020. Menurutnya, nilai-nilai Pancasila dapat dilatih dalam diri siswa melalui kehidupan disekolah maupun budaya di sekolah. Lebih lanjut, Shihab mengatakan, pancasila tidak perlu menunggu momen untuk mengamalkannya. Komunitas dan organisasi dapat menjadi bahan ajar bagi

\footnotetext{
${ }^{6}$ Kemetrian Pendidikan Nasional, Desain Induk Pendidikan Karakter (Jakarta: Kemendikbud, 2010).

${ }^{7}$ Pusat Kurikulum Kemetrian Pendidikan Nasional, Desain Induk Pendidikan Karakter (Jakarta: Kemendikbud, 2011).

${ }^{8}$ Thomas Lickona, Education For Character; How Our School Can Teach Respect and Responsibility (New York: Bantam Books, 1991).
} 
generasi $\mathrm{Z}$ saat ini. Termasuk dalam hal mengamalkan dan membumikan nilainilai Pancasila maupun pendidikan karakter. ${ }^{9}$ Terkait implementasi nilai-nilai pancasila di sekolah sama seperti yang dijelaskan oleh penulis diatas bahwa dibutuhkan konsistensi semua pihak terutama guru, agar setiap pembelajaran disekolah harus dikaitkan dengan nilai-nilai pancasila. Sampai sekarang penulis belum melihat pembudayaan pancasila disekolah seperti pembentukan komunitas pancasila, kelas Berkarakter, kantin Pancasila. Hal-hal unik seperti ini perlu dilakukan disekolah agar menjadi budaya. Masalahnya saat ini, keseriusan kita, butuh dorongan sistem kelembagaan yang efektif dan model kepemimpinan berkarakter.

\section{Konsep Revolusi Mental}

Pengertian Gerakan Nasional Revolusi Mental (GNRM) adalah gerakan nasional yang merubah cara pikir, cara kerja, cara hidup, sikap serta perilaku bangsa Indonesia, mengacu pada nilai-nilai integritas, etos kerja dan gotongroyong berdasarkan pancasila yang beroreantasi pada kemajuan bangsa dan negara. Latar belakang lahirnya Gerakan Nasional Revolusi mental tidak lepas dari permasalahan bangsa yang kian hari mengalami kemerosotan baik wibawa negara, disebabkan para elit politik dan pejabat negara banyak yang terkena kasus korupsi serta tindakan-tindakan amoral dan tidak mencerminkan keteladanan yang baik. Lemahnya persendian ekonomi disebabkan banyak aset-aset negarayang dijual untuk kepentingan kelompok kapitalis, rakyat semakin terhimpit kesengsaraan. Masyarakat semakin bertindak Intoleransi, main hakim sendiri seakan-akan tidak ada lagi pengayom dan pelindung. Generasi cenderung bertindak onar, bebas, konsumsi Narkoba dan Miras menjadi hal yang biasa. Nilai-nilai baik sebagai warisan leluhur hanya sebuah mitos.

Sedangkan tujuan dari Gerakan nasional revolusi mental mencakup; mengubah cara pikir, perilaku, mengubah kesadaran dan membangun sikap mental optimistis dan mewujudkan Indonesia yang berdaulat secara politik, mandiri secara ekonomi dan berkepribadian dalam budaya. Terdapat lima aksi nyata Gerakan Nasional Revolusi mental yang bisa diterapkan di sekolah yaitu;

1. Gerakan Indonesia melayani; disekolah dapat diterapkan lewat pelayanan maksimal kepala sekolah dan guru selalu melayani peserta didik setiap saat baik secara adminstrasi maupun proses pembelajaran serta pengembangan kreatifitas peserta didik yang dapat membentuk karakter mereka.

2. Gerakan Indonesia Bersih; disekolah dapat dilakukan lomba antar kelas setiap 3 bulan sekali, sebelum memulai pelajaran peserta didik diberikan waktu 1015 menit untuk mengontrol dan membersihakn kelas maupun depan kelas serta taman-taman sekolah. Kemudian, peserta didik diberikan kebebasan

\footnotetext{
${ }^{9}$ Www.kemendikbud.go.iddiakses pada tanggal 22 Agustus 2020.
} 
memberikan saran dan masukan dalam kotak saran bagi proses penyelenggaraan pendidikan disekolah tersebut.

3. Gerakan Indonesia Tertib; sekolah dapat menerapkan peraturan bersama guru dan siswa bagi yang melanggar kedisiplinan sekolah diberikan sanksi. Baik guru maupun siswa.

4. Gerakan Indonesia Mandiri; sekolah dapat mendorong kemandirian peserta didik dengan cara koperasi peserta, hasilnya dapat membuka usaha kantin siswa maupun persiapan peserta didik masuk perguruan tinggi. Gerakan untuk melatih peserta didik menjadi wirausahawan muda.

5. Gerakan Indonesia Bersatu; sekolah dapat membentuk komunitas-komunitas seni budaya, club-club peduli sosial, kepramukaan, beladiri dalam membentuk karakter persatuan peserta didik.

Dalam bidang Pendidikan Gerakan Nasional Revolusi Mental dilaksanakan dalam bentuk :

1. Memperkuat kurikulum Pendidikan Kwarganegaraan, Pendidikan Sejarah dan Pendidikan Keagamaan di semua jenjang pendidikan

2. Melaksanakan revolusi mental lewat kegiatan-kegiatan ekstrakurikuler di sekolah

3. Meningkatkan sarana pendidikan yang merata dan digunakan sepenuhnya oleh peserta didik dalam mengembangkan kreatifitasnya

4. Meningkatkan kompetensi guru.

\section{Nilai-Nilai Budaya Bima}

Masyarakata Bima, teramsuk kategori kelompok etnik masyarakat yang masih mempertahankan nilai dan tradisi sebagai warisan identitas budaya. Nilai dan tradisi tersebut, identik dengan sifat dan kebiasaan masyarakat yang dianggap sebagai patuah hidup. Dalam hal ini misalnya nilai agama, nilai hidup, seperti nilai ilmu pengetahuan, nilai ekonomi, nilai keindahan, nilai kekeluargaan maupun nilai-nilai budaya yang berlaku dalam masyarakat Bima. Menurut Hasnun, bahwa sumber nilai pada dasarnya ada empat nilai pokok yaitu; (1) agama, (2) budaya, (3) adat, (4) filsafat. Keempat sumber nilai inilah yang berlaku dalam masyarakat. Menurut Koentjaraningrat dalam Hasnun juga menjabarkan bahwa kebudayaan itu memliki tiga wujud, (1) wujud ideal, kebudyaaan berdasarkan hasil ide dan pikiran manusia seperti, gagasan, nilai, norma dan aturan (2) wujud kelakuan, (3) wujud kebudayaan sebagai benda hasil karya manusi. ${ }^{10}$

Dalam sistem pendidikan nasional kita bahwa kurikulum dapat dibenarkan apabila kurikulum tersebut memuat nilai-nilai budaya dan nilai-nilai luhur bangsa Indonesia. Karena tujuan pendidikan nasional pada akhirnya pembentukan sebuah

${ }^{10}$ Hasnun Anwar. 2017. Penguatan Pendidikan Karakter Berbasis Maja Labo Dahu dan Nggusu Waru (Yogyakarta : LkiS, 2017), 51-53. 
kebudyaan yang beradab. ${ }^{11}$ Menurut Haba dalam M. M Banda ${ }^{12}$ bahwa kearifan lokal mengacu pada berbagai kekayaan budaya yang tumbuh dan berkembang dalam sebuah masyarakat yang dikenal, dipercayai, dan diakui sebagai elemen penting yang mampu mempertebal kohesi sosial ditengah masyarakat.

Dalam dimensi yang lain, fungsi kearifan lokal adalah sebagai berikut : 1) penanda sebuah identitas komunikasi, 2) elemen perekat lintas warga, lintas agama, 3) unsur kulutral yang hidup di masyarakat, 4) warna kebersamaan sebuah komunitas, 5) akan mengubah pola pikir 6) mendrng terbangun kebersamaan sekaligus sebagai mekanisme bersama untuk menepis berbagai kemungkinan yang meredusir bahkan merusak solidaritas kmunal yang dipercaya dan tumbuh atas dasar kesadaran bersama dari komunitas. Beberapa unsur kebudayaan dalam budaya Bima merupakan sumber nilai yang sangat berpengaruh terhadap kehidupan masyarakat Bima sebagaimana tertuang dalam Maja Labo Dahu dan sifat Nggusu Waru.

Adat istiadat dan perilaku keseharian masyarakat Bima tidak bertentangan dengan agama. Tindakan dan perilaku sebagai wujud kelakuan merupakan bagian dari kebudayaan. Setiap karakter masyarakat Bima selalu dilandasi dengan agama. Nilai karakter yang tercermin dari perilaku masyarakat Bima seperti; (1) saronco sarome/Sikap ramah, (2) kaco'i angi/saling menghargai, (3) kasi ade angi/saling menyayangi, (4) karawi kaboju/selalu gotong royong, (5) toa ta dou ma tua/taat padaorang tua, (6) rombo ra kou/kejujuran, (7) nggahi ro eli ma alu/kata dan ucapan yang halus, (8) ruku rawi madantau rawu/tingkah laku yang tidak cacat, (9) lamba angi/saling silaturrahim, (10) loa ra bade ma sandaka ade/kecerdasan yang selalu menjaga hati.

Sementara Motto dan nilai luhur dan prinsip hidup masyarakat Bima yang utama adalah Maja Labo Dahu diantaranya adalah:

1. Tohompara ndai sura dou labo dana artinya biarkanlah saya yang terpenting rakyat dan negeri. Ungkapan ini bermakna ketulusan hati, tidak rakus dan sifat yang selalu mementingkan masyarakat dan bangsa.

2. Tohompa nahu sura dou ma rimpa artinya, tidak penting bagi saya, yang terpenting adalah buat orang banyak.

3. Renta ma rera kapoda ma ade artinya, diikrarkan oleh lidah diperkuat oleh hati. (ciri dari kebulatan tekad yang kuat serta percaya diri dalam melakukan sesuatu)

4. Nggahi Rawi Pahu artinya, berkata dan bertindak (merupakan konsisten apa yang diucapkan dengan tindakan selaras serta tidak bisa berbohong)

5. Karawai Kaboju artinya, gotong royong (maknanya sama giat melakukan kerjasama, saling membantu dan tolong menolong). Masih berlaku sampai

\footnotetext{
${ }^{11}$ Ismail Thoib. Wacana Baru Pendidikan. Yogyakarta : Genta Press, 2008., h. 171.

${ }^{12}$ M. M. Banda. Upaya Kearifan Lokal dalam menghadapi Tantangan Perubahan Kebudayaan. Uinversitas Udayana, https://simdos.unud.ac.id. Diakses tanggal 22 Agustus 2020.
} 
sekarang seperti perpindahan rumah salah satu penduduk, membantu sanak keluarga yang melakukan panen maupun dalam acara upacara pernikahan dan sunatan.

6. Su'u Sawa'u Sia Sawale artinya, diJunjung semampu, ditahan sekuat tenaga. (maknanya ketika seseorang diberikan amanah harus siap menanggung dan memikul tanggungjawab yang diberikan tanpa mengeluh sedikitpun)

7. Takwa. Artinya, taaat terhadap perintah serta menjauhi larangan Allah Swt. Wujud ketaatan terhadap Tuhan Yang Maha Esa menjadi karakter sosial yang kuat seperti berperilaku baik dalam masyarakat, tidak sombong serta selalu mawas diri.

Selanjutnya untuk menjabarkan gamabaran adannya nilai integrasi nilai pendidikan karakter, revolusi mental dan nilai budaya Bima, dapat dilihat dalam uraian tabel berikut ini

Tabel. 1.

Integrasi Nilai Pendidikan Karakter, Revolusi mental dan Nilai Budaya Bima

\begin{tabular}{|c|c|c|}
\hline 18 Nilai Karakter Bangsa & Revolusi mental & Nilai Maja Labo Dahu \\
\hline Jujur & Integritas & $\begin{array}{l}\text { Tohompara Nahu Sura Dou } \\
\text { Labo Dana (adil, tidak } \\
\text { serakah, cinta rakyat) }\end{array}$ \\
\hline Toleransi & Etos kerja & $\begin{array}{l}\text { Edera Nahu Sura Dou } \\
\text { Marimpa }\end{array}$ \\
\hline Disiplin & Gotong-royong & $\begin{array}{l}\text { Renta Ma Rera, Kapoda ma } \\
\text { Ade, Karawi Ba Weki (tekad, } \\
\text { teguh, prinsip, kuat) }\end{array}$ \\
\hline Kerja keras & & $\begin{array}{l}\text { Nggahi Rawi Pahu (prinsip, } \\
\text { konsisten, patuh dan } \\
\text { bertanggungjawab) }\end{array}$ \\
\hline Kreatif & & $\begin{array}{l}\text { Karawi Kaboju (Gotong } \\
\text { royong, persatuan dan } \\
\text { kerjasama) }\end{array}$ \\
\hline Mandiri & & $\begin{array}{l}\text { Su'u Sawa'u Sia Sawale } \\
\text { (Tanggungjawab, pantang } \\
\text { menyerah, amanah dan } \\
\text { ikhlas) }\end{array}$ \\
\hline Demokratis & & $\begin{array}{l}\text { Mafaka Ro Dampa (Mufakat } \\
\text { dan Kerjasama) }\end{array}$ \\
\hline Rasa ingin tahu & & $\begin{array}{l}\text { Iu Ade Angi } \\
\text { (Empati) }\end{array}$ \\
\hline Semangat & & Lamba Angi (silaturahmi) \\
\hline Cinta tana air & & Rombo Ra Kou (Jujur) \\
\hline Menghargai & & Saronco Sarome (Ramah) \\
\hline Bersahabat & & \\
\hline Cinta damai & & \\
\hline Gemar membaca & & \\
\hline Peduli lingkungan & & \\
\hline Peduli sosial & & \\
\hline Tanggungjawab & & \\
\hline Religius & & \\
\hline
\end{tabular}




\section{Penutup}

Dalam implementasinya dilapangan Pendidikan Karakter tidak boleh lepas dari peran sentral orangtua sebagai Kampus utama peserta didik. Di lingkungan keluarga lah peserta didik membudayakan perilaku sosial yang berlaku di masyarakat, di lingkungan keluarga juga peserta didik terbentuk mental, emosional serta karakternya. Untuk pendidikan karakter berbasis keluarga sudah saatnya dilembagakan secara serius dan diperhatikan oleh pemerintah bukan memberikan kewenangan penuh sekolah maupun lembaga lainnya. Integrasi Pendidikan Karakter, Revolusi Mental dan nilai-nilai budaya Bima yang sangat terkait sekali adalah Jujur (Nilai Karakter), Integritas (Revolusi Mental), Rombo Ra Kou (Nilai Maja Labo Dahu-Bima). Kemudian, Kerja Keras (Nilai Karakter), Etos Kerja (Revolusi Mental), Karawi Kaboju dalam Nilai-nilai budaya Bima. Begitupun dengan nilai-nilai tanggungjawab dalam pendidikan karakter yang memiliki keterkaitan dengan gotong royong di Revolusi mental yang juga memiliki kesamaan dengan Karawi Kaboju dalam nilai-nilai budaya Bima. Ketiga aspek sumber nilai baik dalam pendidikan karakter, revolusi mental dan nilai budaya Bima semuanya memiliki keterkaitan dan saling mendukung dalam pembentukan karakter peserta didik disekolah. Untuk itu sangat perlu diterapkan disetiap jenjang pendidikan mulai dari tingkat SD, SMP, SMA sampai Tingkat Perguruan Tinggi. Hal ini dilakukan agar seluruh nilai-nilai yang ada menjadi kebudayaan yang menyatu dalam diri setiap peserta didik.

\section{DAFTAR PUSTAKA}

Banda, M. M. Banda. Upaya Kearifan Lokal dalam menghadapi Tantangan Perubahan Kebudayaan. Uinversitas Udayana, https://simdos.unud.ac.id. Diakses tanggal 22 Agustus 2020.

Hasnun, Anwar. 2017. Penguatan Pendidikan Karakter Berbasis Maja Labo Dahu dan Nggusu Waru. Yogyakarta : LkiS, 2017.

Hidayat, Rakhmat. Pengantar Sosiologi Kurikulum. Jakarta : Rajawali Pers, 2011.

Instruksi Presiden Republik Indonesia Nomor 12 Tahun 2016 Tentang Gerakan Nasional Revolusi Mental

Kemetrian Pendidikan Nasional, Desain Induk Pendidikan Karakter. Jakarta: Kemendikbud, 2010.

Lickona, Thomas. Education For Character; How Our School Can Teach Respect and Responsibility. New York: Bantam Books, 1991.

Masnur, Musclih. Pendidikan Karakter. Jakarta : Bumi Aksara, 2011.

Peraturan Menteri Pendidikan dan Kebudyaaan Nomor 23 Tahun 2015 Tentang Penumbuhan Budi Pekerti

Pusat Kurikulum Kemetrian Pendidikan Nasional, Desain Induk Pendidikan Karakter. Jakarta: Kemendikbud, 2011.

Republik Indonesia. "Undang-Undang RI Nomor 20 Tahun 2003 tentang Sistem Pendidikan Nasional” (Cet. V; Jakarta: Sinar Grafika, 2013. 
Samani Mushlas \& Hariyanto. Konsep dan Model Pendidikan Karakter. Bandung : Rosda Karya, 2014.

Susanto Heri. Seputar Pembelajaran Sejarah. Yogyakarta : Aswaja Presindo, 2014.

Suyanto. Pendidikan Karakter Teori dan Aplikasi. Jakarta : Rineka Cipta, 2010. Thoib, Ismail Thoib. Wacana Baru Pendidikan. Yogyakarta : Genta Press, 2008. www.kemendikbud.go.iddiakses pada tanggal 22 Agustus 2020. 